\title{
An easy drying schedule for Tectona grandis through vacuum press drying
}

\author{
Sachin Gupta ${ }^{1}$, V. S. Kishan Kumar ${ }^{1}$ \\ ${ }^{1}$ Forest Products Division, Forest Research Institute, Dehradun, India.
}

\begin{abstract}
Drying experiments were conducted on $25 \mathrm{~mm}$ thick samples of Tectona grandis with the aim of evolving a drying schedule under vacuum press drying. The experiments were conducted under eleven different combinations of water temperature and pressure level inside the chamber. The results were analyzed to understand which combination resulted in highest percentage moisture content (MC) reductions from different initial MC ranges above and below the fiber saturation point of the species. Based on this, a simple schedule was formulated for drying planks of this timber. No serious drying degrades could be observed in the samples in spite of taking them through different drying cycles. It was found by applying this schedule that $25 \mathrm{~mm}$ thick samples of teak could be dried to around 7.6\% MC levels from around $24 \%$ initial MC effectively in three steps. The study illustrated the usefulness of vacuum press drying technique in fast drying of teak.
\end{abstract}

Keywords: Drying rate; moisture content; pressure; teak wood; vacuum.

\section{Introduction}

Vacuum drying of wood has caught the imagination of wood seasoning industries due to much lower drying times. The technique is based on the fact that water in the wood boils at lower temperatures if the ambient pressure in which the wood stack is heated is lowered. The atmospheric pressure also creates a pressure gradient inside the wood helping in faster moisture movement. This helps in enhancing the rate of drying especially through the end grain. The permeability of the wood being dried would obviously affect the overall drying process.

The rapid moisture reduction due to vacuum based drying has been reported by many workers on a variety of species. Twenty-five $\mathrm{mm}$ thick samples of Oriental beech (Fagus orientalis) and Scots pine (Pinus sylvestris) could be brought down from $46-47 \%$ moisture to $10-13 \%$ moisture content levels in just 48 hours using vacuum drying assisted by infrared heating (ALTUN et al., 2011). Leiker et al. (2004) reported moisture losses between $0.017 \% / \mathrm{h}$ and $0.075 \% / \mathrm{h}$ in beech samples when they were vacuum dried with micro wave heating. Trebula; Dekret (1984) reported 3-5 times lower drying times for Robinia spp. samples of $50 \mathrm{~mm}$ thickness under vacuum drying compared to conventional air-drying. A recent report highlighted the use of vacuum drying in getting high drying rates even below fiber saturation point in the case of Tectona grandis (KISHAN KUMAR et al., 2016). It has been reported that samples of Populus deltoides could be dried from $90 \%$ MC levels to less than $15 \%$ MC levels effectively in two steps (KISHAN KUMAR et al., 2008).

Tectona grandis (Teak) is probably the most important species in India which can be ascertained from the fact that almost every wood quality parameter is usually compared with that of this species. It is a moderately refractory species as far as its kiln seasoning characteristics are concerned and has been assigned schedule V (Bureau of Indian Standards, 1993). It is suggested that for $25 \mathrm{~mm}$ thick planks of this species requires 13 to 15 days to dry to near $12 \%$ MC levels by following this schedule.

In the above context, an attempt was made to evolve a drying schedule for teak samples using vacuum press drying technology by employing random temperature-pressure combinations. 


\section{Materials and Methods}

The experiments were carried out in a MASPELL Vacuum Press Dryer (VPD). This unit is explained in detail in an earlier paper (KISHAN KUMAR et al., 2008). Heated water circulating through platens provides heat to the wood planks kept between adjacent platens through conduction. A ring type vacuum pump facilitates reducing pressure in the chamber whenever required.

Fifty-three samples of $600 \mathrm{~mm}$ length and 50 to 150 $\mathrm{mm}$ widths were prepared from $25 \mathrm{~mm}$ thick teak planks plain sawn from a single log for the study. All these samples were stacked between the top two platens. The initial weights of these samples were recorded prior to placing them between the platens. The spaces between the remaining platens were stacked by filler material to complete the charge of the kiln.

The temperature and pressure controls of the VPD were manually operated with the temperature of the circulating hot water being read on the control panel and the pressure inside the chamber being read on a pressure gauge attached to the chamber for that purpose. Eleven different combinations of water temperature and pressure inside the chamber were used which are designated as treatments $\mathrm{T} 1$ through $\mathrm{T} 11$. These treatments are listed in Table 1.

The samples were preheated for 6 hours with hot water flowing through the platens prior to applying a vacuum-temperature treatment. For this purpose, the water temperature was maintained at 5 degrees below the treatment temperature. The preheating was aimed at allowing the teak samples to attain uniform temperatures throughout their thicknesses. After pre-heating, the temperature was raised to the desired level. As soon as this temperature was achieved, the vacuum pump was switched on and the desired pressure level was achieved inside the chamber. When the desired pressure level was achieved, the water heaters and vacuum pump were switched off. It was noticed that the vacuum and temperature levels inside the kiln were sustained for about further 30 minutes. Thus, one such drying run lasted almost 7 hours (preheating, increasing temperature to the desired level, applying vacuum, maintaining vacuum and temperature after switching off the water heaters and vacuum pump). One drying run constituted applying one such treatment. The sample weights were monitored after each such drying run. The different treatments were applied one after another on different days following no particular sequence.

Table 1. The pressure-temperature treatments used in the study.

\begin{tabular}{ccc}
\hline Treatment & Temperature $\left({ }^{\circ} \mathrm{C}\right)$ & Pressure $(\mathrm{mbar})^{*}$ \\
\hline $\mathrm{T} 1$ & 80 & 913 \\
$\mathrm{~T} 2$ & 80 & 573 \\
$\mathrm{~T} 3$ & 80 & 353 \\
$\mathrm{~T} 4$ & 90 & 873 \\
$\mathrm{~T} 5$ & 90 & 413 \\
$\mathrm{~T} 6$ & 90 & 313 \\
$\mathrm{~T} 7$ & 70 & 473 \\
$\mathrm{~T} 8$ & 70 & 873 \\
$\mathrm{~T} 9$ & 70 & 373 \\
$\mathrm{~T} 10$ & 60 & 373 \\
$\mathrm{~T} 11$ & 60 & 513
\end{tabular}

${ }^{\star}$ Note: (The pressure on the gauge was in -100, -200 mbar below the atmospheric pressure. Hence, a pressure of $913 \mathrm{mbar}$ in the Table corresponds to a reading of -100 on the gauge).

The moisture contents of the samples were estimated by oven-drying them at the end of the experiment. Efficiency of a particular treatment was assessed by calculating the Percentage reduction in moisture content $\left(\mathrm{MC}_{\mathrm{r}}\right)$ due to each treatment (KISHAN KUMAR et al., 2016). The initial moisture contents $\left(\mathrm{MC}_{\mathrm{i}}\right)$ of samples showed variations due to partial drying of samples during preparation. As a result, unequal replications in different $M C_{i}$ ranges were encountered 
during progressive drying and analysis of data has been done accordingly.

Collected data on samples was grouped into ranges below and above the Fiber Saturation Point (FSP). Further subranges have also been made for $\mathrm{MC}_{\mathrm{i}}$ values above FSP in view of en-mass flow of free water sensitive to capillarity. Drying below FSP being diffusion phenomena, the $\mathrm{MC}_{\mathrm{i}}$ data in this range were kept as such. Data with less than three replicates in a particular $\mathrm{MC}_{\mathrm{i}}$ range was not considered for analysis.

The values of $\mathrm{MC}_{\mathrm{r}}$ (percentage) for a given $\mathrm{MC}_{\mathrm{i}}$ interval range were transformed suitably (Ahrens et al., 1990) and analysis of variance (ANOVA) was carried out on the transformed values. For a clearer understanding of the efficiency of each treatment, Duncan's subsets were formed to arrive at the best treatment in a particular $\mathrm{MC}_{\mathrm{i}}$ range. The best treatments in each $\mathrm{MC}_{\mathrm{i}}$ range were considered for developing a drying schedule.

Ten samples which showed $\mathrm{MC}_{\mathrm{i}}$ approximately in the 19$30 \%$ range (based on their calculated oven dry weights) and prepared from plank from the same log as in the original experiment were used for testing the schedule. These samples were placed between two adjacent platens and the required pressure-temperature combinations were applied as before. The only difference was that the samples were not taken out for weighing in between. After the desired steps were completed, the samples were taken out and their weights were recorded. Each of these were then oven dried to calculate their actual $\mathrm{MC}_{\mathrm{i}}$ and final moisture content $\left(\mathrm{MC}_{\mathrm{f}}\right)$.

\section{Results and Discussion}

The FSP of teak is reported to be around 19\% (Jain et al, 2000). Thus, an $\mathrm{MC}_{\mathrm{i}}$ range of $10 \%$ to $19 \%$ was formed below this value. The ranges above FSP were divided into 19\%-30\% and 30\%-50\%
A total of 36 readings were found to lie in the $30 \%-50 \%$ $\mathrm{MC}_{\mathrm{i}}$ range across various treatments applied on the 53 samples. As drying progressed, 93 readings were found to lie in the 19\%-30\% $\mathrm{MC}_{\mathrm{i}}$ range under different treatments. Once most of the samples dried to below FSP levels, there were 230 $\mathrm{MC}_{\mathrm{i}}$ readings lying in the $10-19 \%$ range across various treatments applied. The percentage reductions in the moisture contents due to applied treatments $\left(\mathrm{MC}_{\mathrm{r}}\right)$ were calculated as explained in the methodology section. The $\mathrm{MC}_{\mathrm{r}}$ values had a wide range from as small as $2.43 \%$ to $33.15 \%$ depending on the pressure-temperature treatment applied and the $\mathrm{MC}_{\mathrm{i}}$ range to which the samples belonged. This corresponds to drying rates of $0.35 \% / \mathrm{h}$ to $4.74 \% / \mathrm{h}$. There are reports of drying rates from $0.7 \% / \mathrm{h}$ to $20 \% / \mathrm{h}$ for beech samples under vacuum drying (ALTUN et al., 2011; CIVIDINI et al., 2003).

The calculated and transformed $\mathrm{MC}_{\mathrm{r}}$ values were analyzed through one-way ANOVA (Table 2) from which it can be seen that reductions in all the three $\mathrm{MC}_{\mathrm{i}}$ ranges differ significantly with applied treatments.

Table 2. ANOVA of $M C_{r}$ in the three $M C_{i}$ ranges.

\begin{tabular}{|c|c|c|c|c|c|}
\hline $\begin{array}{c}\mathrm{MC}_{\mathrm{i}} \\
\text { Range }\end{array}$ & $\begin{array}{l}\text { Source of } \\
\text { variation }\end{array}$ & $\mathrm{df}$ & $\begin{array}{l}\text { Mean } \\
\text { Square }\end{array}$ & $\mathrm{F}$ & Sig. \\
\hline \multirow{2}{*}{$50-30 \%$} & Treatments & 4 & 203.38 & \multirow{2}{*}{22.98} & \multirow[t]{2}{*}{$<0.001$} \\
\hline & Error & 31 & 8.85 & & \\
\hline \multirow{2}{*}{$30-19 \%$} & Treatments & 5 & 827.34 & \multirow{2}{*}{78.42} & \multirow[t]{2}{*}{$<0.001$} \\
\hline & Error & 87 & 10.55 & & \\
\hline \multirow{2}{*}{$19-10 \%$} & Treatments & 9 & 1855.39 & \multirow{2}{*}{149.51} & \multirow[t]{2}{*}{$<0.001$} \\
\hline & Error & 220 & 12.41 & & \\
\hline
\end{tabular}

Table 3 gives the actual average values of $\mathrm{MC}_{\mathrm{r}}$ obtained under different treatments for different $M C_{i}$ ranges and grouped into different subsets using Duncan's homogeneity test.

It is pertinent to note that none of the 53 samples exhibited any type of drying degrade like surface cracking, end splitting or deformation. This is in spite of the fact that all of 
them were subjected to the 11 vacuum-temperature treatments during the whole experiment.

Table 3. Average moisture content reductions in (\%) under different treatments grouped into Duncan's subsets

\begin{tabular}{|c|c|c|c|c|c|c|c|c|}
\hline \multirow{2}{*}{$\begin{array}{c}\mathrm{MC}_{\mathrm{i}} \\
\text { Range }\end{array}$} & \multirow{2}{*}{ Treat. } & \multicolumn{7}{|c|}{ Subsets of $\mathrm{MC}_{\mathrm{r}}$} \\
\hline & & 1 & 2 & 3 & 4 & 5 & 6 & 7 \\
\hline & T9 & 7.09 & & & & & & \\
\hline \multirow[t]{6}{*}{$50-30 \%$} & $\mathrm{~T} 1$ & 8.27 & & & & & & \\
\hline & T8 & 10.48 & & & & & & \\
\hline & T10 & & 19.95 & & & & & \\
\hline & T7 & & & 26.77 & & & & \\
\hline & T9 & 4.31 & & & & & & \\
\hline & $\mathrm{T} 1$ & 5.77 & & & & & & \\
\hline \multirow[t]{8}{*}{$30-19 \%$} & T8 & & 12.23 & & & & & \\
\hline & $\mathrm{T} 10$ & & 13.53 & 13.53 & & & & \\
\hline & T7 & & & 17.02 & & & & \\
\hline & T2 & & & & 29.34 & & & \\
\hline & T9 & 2.43 & & & & & & \\
\hline & $\mathrm{T} 1$ & 3.43 & & & & & & \\
\hline & $\mathrm{T} 4$ & & 6.86 & & & & & \\
\hline & T11 & & 9.53 & & & & & \\
\hline \multirow[t]{6}{*}{$19-10 \%$} & $\mathrm{~T} 7$ & & & 16.97 & & & & \\
\hline & $\mathrm{T} 10$ & & & 18.83 & 18.83 & & & \\
\hline & T6 & & & & 21.41 & 21.41 & & \\
\hline & $\mathrm{T} 3$ & & & & & 24.28 & 24.28 & \\
\hline & $\mathrm{T} 2$ & & & & & & 26.43 & \\
\hline & T5 & & & & & & & 33.15 \\
\hline
\end{tabular}

It can be seen from Table 3 that the maximum reduction in MC below FSP is caused by $\mathrm{T} 5$ by about $33.15 \%$. In the above FSP ranges of $19-30$ and $30-50 \%$, T2 and T7 respectively resulted in higher MC reductions. These two treatments do perform reasonably well in the below FSP level as well (with $\mathrm{MC}_{\mathrm{r}}$ of $26.43 \%$ and $16.97 \%$ respectively). Thus, we can effectively bring down MC of teak from an initial value of $50 \%$ using three temperature-pressure steps as given in Table 4.

It is pertinent to mention that an earlier work reported that it is possible to dry $25 \mathrm{~mm}$ thick Populus deltoides samples from 90\% MC to below FSP levels in two simple steps using vacuum press drying (KISHAN KUMAR et al., 2008).
Table 4. Schedule for Teak wood.

\begin{tabular}{lll}
\hline MC range $(\%)$ & Temperature $\left({ }^{\circ} \mathrm{C}\right)$ & Pressure $(\mathrm{mbar})$ \\
\hline $50-30$ & 70 & 473 \\
$30-19$ & 80 & 573 \\
$19-10$ & 90 & 413 \\
\hline
\end{tabular}

An example of implementing the schedule with the schedule given in Table 4 for an $\mathrm{MC}_{\mathrm{i}}$ of $50 \%$ can be illustrated as shown in Table 5. Thus, one can arrive at near 12\% MC from an initial $50 \%$ in 4 steps.

Table 5. An illustration of the schedule for drying from $50 \%$ Initial MC.

\begin{tabular}{ccc}
\hline Temperature $\left({ }^{\circ} \mathrm{C}\right)$ & Pressure (mbar) & MC $(\%)$ \\
\hline 70 & 473 & 50 \\
70 & 473 & 37 \\
80 & 573 & 27 \\
90 & 413 & 19 \\
\hline \multicolumn{3}{c}{} \\
\hline
\end{tabular}

\section{Testing of the drying schedule}

The above schedule was tested on 10 teak samples which were obtained from the same log from which the earlier 53 samples were prepared. These ten samples had approximate initial MC in the range of $25-30 \%$ (based on their calculated oven-dry weights). $25 \%$ was assumed as the initial MC to test the schedule. With the calculated $\mathrm{MC}_{\mathrm{r}}$ values, the steps for drying these samples from $25 \% \mathrm{MC}_{\mathrm{i}}$ can be given as in Table 6.

Table 6. Steps for drying from 30\% Initial MC.

\begin{tabular}{ccc}
\hline Temperature $\left({ }^{\circ} \mathrm{C}\right)$ & Pressure (mbar) & MC $(\%)$ \\
\hline 80 & 573 & 25.0 \\
90 & 413 & 17.7 \\
90 & 413 & 11.8 \\
\hline \multicolumn{4}{r}{} \\
\hline
\end{tabular}

Thus only 3 runs were applied to the ten samples exactly as was done during the experiment. The samples were taken out on the $4^{\text {th }}$ morning after allowing them to cool in the 
nights after each run and their final weights were recorded. The oven dry weights of all these samples were estimated in the laboratory and their actual $\mathrm{MC}_{\mathrm{i}}$ and $\mathrm{MC}_{\mathrm{f}}$ were calculated. These are given in Table 7.

Table 7. Initial and final moisture contents of test samples.

\begin{tabular}{cccccc}
\hline Sample $\mathrm{N}^{\circ}$. & Actual Oven dry weight $(\mathrm{gm})$ & Initial weight $(\mathrm{gm})$ & $\mathrm{MC}_{\mathrm{i}}$ & Final weight $(\mathrm{gm})$ & $\mathrm{MC}_{\mathrm{f}}$ \\
\hline 1 & 370 & 441 & 19.19 & 388 & 4.86 \\
2 & 382 & 460 & 20.39 & 402 & 5.21 \\
3 & 369 & 451 & 22.22 & 393 & 6.50 \\
4 & 347 & 424 & 22.28 & 374 & 7.86 \\
5 & 675 & 834 & 23.56 & 727 & 7.70 \\
6 & 355 & 442 & 24.51 & 388 & 9.30 \\
7 & 359 & 448 & 24.79 & 379 & 5.57 \\
8 & 646 & 808 & 25.08 & 712 & 10.22 \\
9 & 352 & 443 & 25.85 & 387 & 9.94 \\
10 & 326 & 422 & 29.45 & 355 & 8.90 \\
\hline Mean & $\mathbf{4 1 8 . 0 8}$ & $\mathbf{5 1 7 . 3 0}$ & $\mathbf{2 3 . 7 3}$ & $\mathbf{4 5 0 . 5 0}$ & $\mathbf{7 . 6 1}$ \\
\hline Standard Deviation & $\mathbf{1 2 8 . 8 3}$ & $\mathbf{1 6 0 . 5 8}$ & $\mathbf{2 . 9 2}$ & $\mathbf{1 4 2 . 3 7}$ & $\mathbf{1 . 9 9}$ \\
\hline Coefficient. of Variation (\%) & $\mathbf{3 0 . 8 1}$ & $\mathbf{3 1 . 0 4}$ & $\mathbf{1 2 . 3 2}$ & $\mathbf{3 1 . 6 0}$ & $\mathbf{2 6 . 1 0}$ \\
\hline
\end{tabular}

Thus, it can be seen that after three runs, the samples have attained 7.61\% MC (against 7.9\% predicted in Table 6). The test indicates that overall drying rate after 3 runs (effectively lasting for 21 hours) resulted in a moisture reduction of $16.2 \%$ accounting for $0.77 \% / \mathrm{h}$. This is very similar to the drying rates of $0.7 \% / \mathrm{h}$ and $0.75 \%$.h reported for beech and scots pine under radio frequency heated vacuum drying (ALTUN et al., 2011). A look at Table 6 in fact suggests that only two runs would be required to bring down the MC from a mean 25\% to near $12 \%$. The study clearly illustrates the effectiveness of seasoning teak planks faster using vacuum press drying technique.

\section{Conclusions}

An easy drying schedule has been developed for teak that can be applied in a vacuum press dryer which would save a lot of kiln operation time. The study indicates that vacuum press drying can be a powerful tool in fast drying of $25 \mathrm{~mm}$ thick teak. In effect, the planks can be dried from 50\% MC levels to the required value below FSP in three simple steps.
The developed schedule was used to test in drying $25 \mathrm{~mm}$ thick samples with mean initial MC of around $24 \%$ to nearly 7.6\% final MC in just three runs lasting 21 hours. It would be advisable to test this schedule at Industrial level and make suitable adjustments/refining.

\section{Acknowledgments}

The authors wish to thank the Director, FRI and Head, Forest Products Division for their constant encouragement. The help rendered by the staff of saw mill, WWF Discipline and WS Discipline are highly appreciated. The interest shown by Dr. NK Upreti of WS Discipline has been of critical help during the entire experiment.

\section{References}


AHRENS, W.H.; D.J.COX, D.J; BUDHWAR, G. Use of arcsine and square root transformations for subjectivity determined percentage data. Weed Science, v. 38, p. 452-458, 1990.

ALTUN, S.; YAPICI, F.; KORKMAZ, Z. Effects of vacuum drying with infrared heating on some properties of wood. Annals of Warsaw University of Life Sciences- SGGW: Forestry and Wood Technology, v. 73, p. 16-22, 2011.

BUREAU OF INDIAN STANDARDS. Indian standard Seasoning of Timber - Code of Practice, IS 1141, 1993. pp. 26.

CIVIDINI, R.; VALENTI, L.; ALLEGRETTI, O. (2003). Investigation on moisture content gradients in Vacuum - Press drying process of Beech elements. In: PROCEEDINGS OF 8TH INTERNATIONAL IUFRO WOOD DRYING CONFERENCE, Brasov, Romania, p. 141- 146, 2003.

JAIN, J.D.; GURU, R.D.; SINGH, R. Physical and mechanical properties of Mangifera indica (Mango) and Syzegium spp (Jamun) from Dehra Dun (U.P.). Indian Forester, v. 126, n.9, p. $948-956,2000$.

KISHAN KUMAR, V.S.; UPRETI, N.K.; GUPTA, S. Scope of vacuum press drying for fast removal of moisture below fiber saturation point. Drying Technology, v. 34, n. 10, p. 12041209, 2016.

KISHAN KUMAR, V.S.; GUPTA, S.; SHARMA, C.M. Studies on vacuum press drying of Populus deltoides. Indian Forester, v. 134, n. 6, p. 835-42, 2008.

LEIKER, M.; ADAMSKA, M.A.; GÜTTEL, R.; MOLLEKOPF, N. Vacuum Microwave Drying of Beech: Property Profiles and Energy Efficiency. In: PROCEEDINGS COST E15 CONFERENCE, Athens, Greece, 2004.

TREBULA, P. DEKRET, A. Vacuum drying of robinia timber. Holzindustrie, v. 36, n. 4, p. 115-116, 1984. 